\title{
Diffusion Coating for Ni-Cr-Fe Alloy by the Pack Cementation Process
}

\author{
A. S. Khalil
}

Metallurgy and Mining Department, Tabbin Institute for Metallurgical Studies, Cairo, Egypt

A pack cementation is a coating technique frequently used to apply protective coating on metal substrates to protect them from corrosion damage and high temperature oxidation [1]. The process is basically an in situ chemical vapor deposition followed by a solid state diffusion process at higher temperature. For the nickel-base superalloys, Al is most commonly deposited by this method to form nickel aluminide coatings. In some cases, inclusion of $\mathrm{Cr}$ in the coating layer may be desirable to enhance the high temperature corrosion resistance [2]. The Aluminum in the coated substrate surface oxidizes preferentially to form a thin and dense alumina layer that acts as a diffusion barrier and hence substantially reduces the substrate oxidation at elevated temperatures.

In this study, SEM and EDX analyses techniques were used to investigate the pack cementation coating for $\mathrm{Ni}-20 \mathrm{Cr}-10 \mathrm{Fe}$ (wt \%) alloy coated at temperatures; 800, 1000 and $1100{ }^{\circ} \mathrm{C}$ at constant time. The samples were in the form of $15 \mathrm{~mm}$ side cubes ground to 500-grade finish using SiC abrasive paper. The pack powder (500 g for each retort) consists of pure Al powder $(30 \% \mathrm{wt})$, Ferro-chrome powder $(35 \%$ wt), $\mathrm{Al}_{2} \mathrm{O}_{3}$ filler $(30 \% \mathrm{wt})$ and $\mathrm{NH}_{4} \mathrm{Cl}$ activator $(5 \% \mathrm{wt})$. Before being put into the sealed cylindrical steel retorts, the powder were thoroughly mixed and further ground with mortar and pestle and dried at $800{ }^{\circ} \mathrm{C}$ for 2 hours. Samples were then packed in the powder-filled retorts and resealed. Each retort was heated to the required temperature and held for 6 hour duration and then cooled inside the furnace to room temperature.

As shown in Figure 1(a) a low magnification back scattered electron image of cross section of the sample coated at $1100{ }^{\circ} \mathrm{C}$ revealing that the coating was rather uniform. Microhardness measurements indicate that the formed layers are hard showing a fourfold increase of hardness relative to that of the substrate alloy (193 HV). The measured microhardness values of the coatings were 761, 778 and 792 $\mathrm{HV}$ for samples processed at 800,1000 and $1100{ }^{\circ} \mathrm{C}$ respectively. Several cracks were observed along the coatings as shown in figure 1(a) which might arise from the subsequent preparations of the samples (cutting, grinding and polishing) and are indicative of the brittle nature of the coatings. XRD results revealed that the major constituent of the formed coatings to be the cubic intermetallic $\mathrm{AlNi}_{3}$ phase as depicted in figure 1(b) which shows the corresponding peak patterns for that phase for the sample treated at $800{ }^{\circ} \mathrm{C}$. Figure 2(a) shows an EDX elemental mapping of the planar distribution of three elements $\mathrm{Al}, \mathrm{Cr}$ and $\mathrm{Ni}$ of the coating layer for the sample coated at $1000{ }^{\circ} \mathrm{C}$. A progressive increase of coating thickness was observed with higher coating temperatures, the measured thickness values were 67,135 and $170 \mu \mathrm{m}$ for samples processed at 800,1000 and $1100{ }^{\circ} \mathrm{C}$ respectively. In Figure $2(\mathrm{~b})$ a plot of the natural logarithmic coating thickness versus the reciprocal coating temperatures showed a liner relationship which could be described by Arrhenius-type equation for the investigated temperature range [3]. Using a linear fit, the activation energy was calculated for the coating process to be $38.61 \mathrm{~kJ} / \mathrm{mol}$.

In conclusion, uniform and hard coatings of nickel aluminide could be formed on Ni-Cr-Fe alloys using the pack cementation process for the indicated powder composition, processing temperatures and time as was shown in this investigation. Further work on coatings for the same alloy under lower processing temperatures and shorter time is in progress. 
References:

[1] Metallurgical and Ceramic Protective Coatings, ed. K. H. Stern (Springer, Berlin) p. 236.

[2] Heat Resistant Materials, ed. J. R. Davies (ASM International, Materials Park) p.335.

[3] Min Qiao and Chungen Zhou, Surface and Coatings Technology 206 (2012), p. 2899.
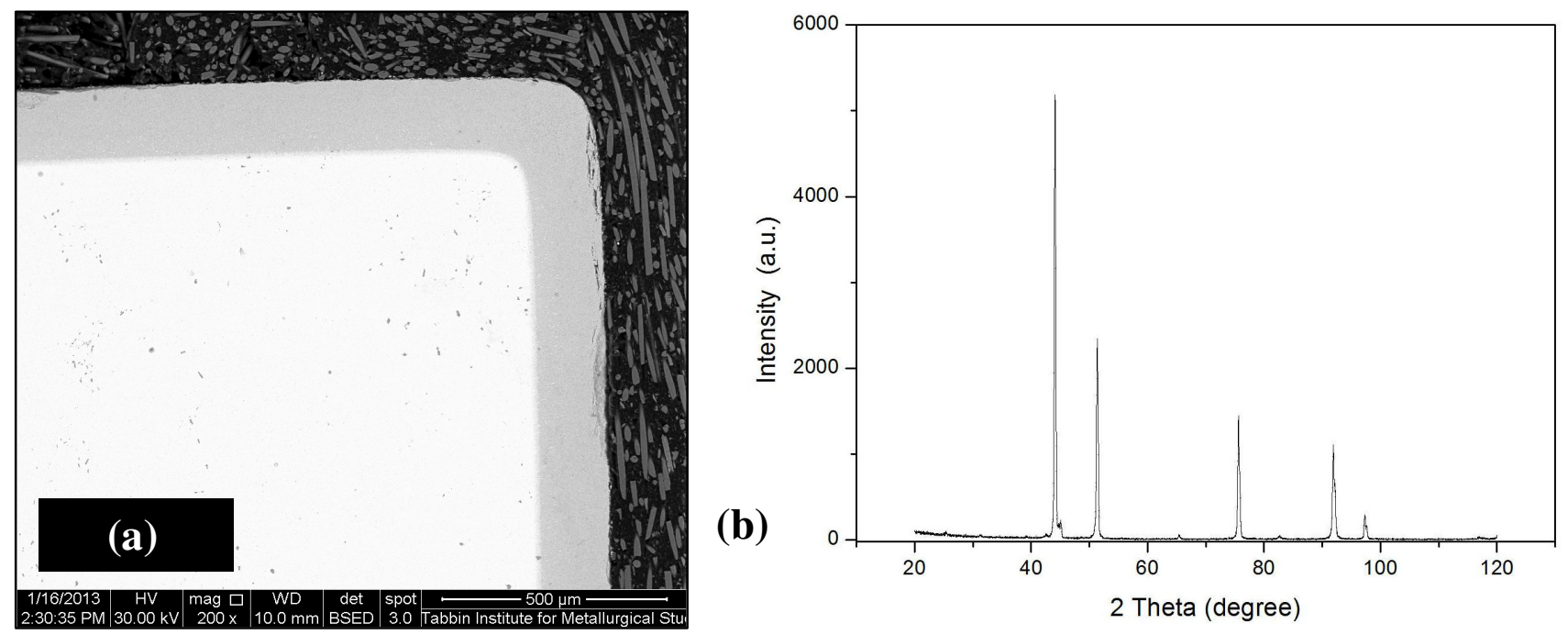

Figure 1. A low magnification cross-sectional back scattered electron image of the sample coated at $1100{ }^{\circ} \mathrm{C}$ (a) and XRD pattern for the sample coated at $800{ }^{\circ} \mathrm{C}(\mathbf{b})$.

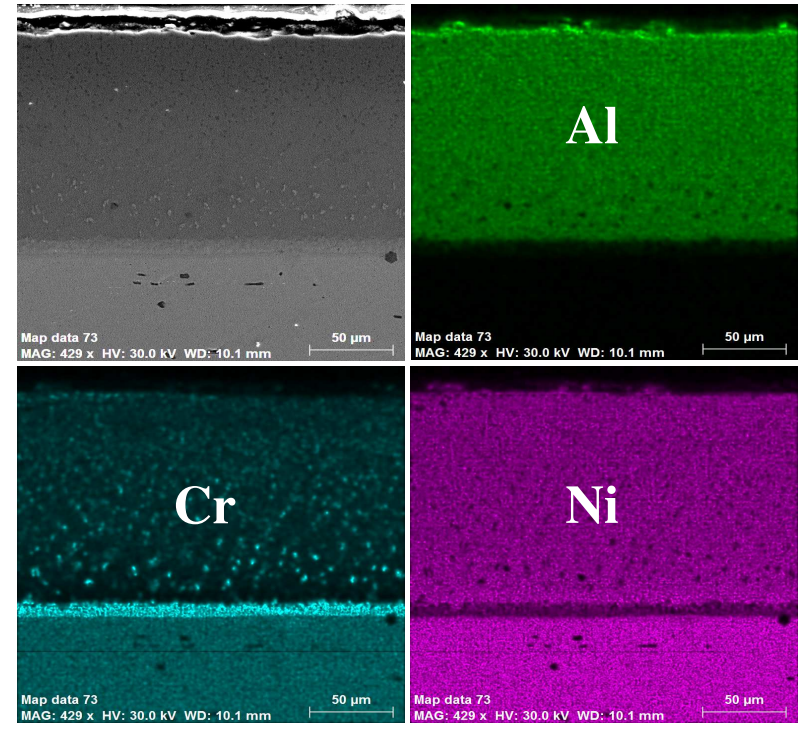

(a)

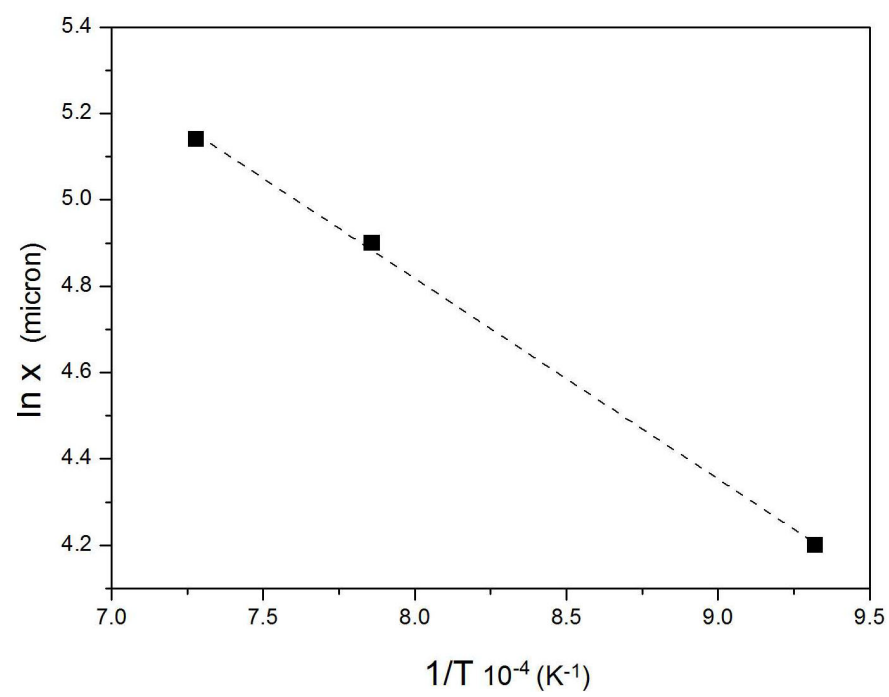

(b)

Figure 2. A cross-sectional secondary electron image of the sample coated at $1000{ }^{\circ} \mathrm{C}$ and the corresponding EDX elemental mapping of $\mathrm{Al}, \mathrm{Cr}$ and $\mathrm{Ni}$ (a). An Arrhenius plot of the logarithmic coating thickness versus coating temperature for the investigated temperature range (b). 